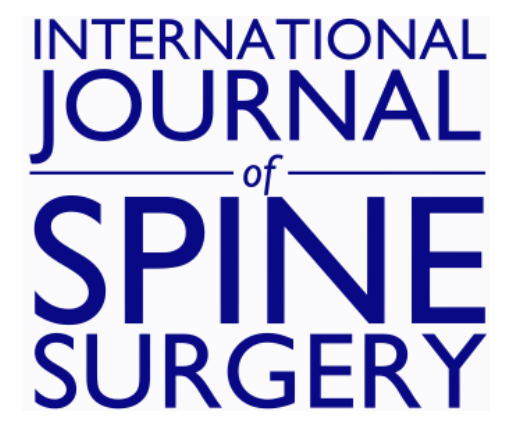

\title{
Surgical Revision after Sacroiliac Joint Fixation or Fusion
}

Katie Spain and Timothy Holt

Int J Spine Surg 2017, 11 (1)

doi: https://doi.org/10.14444/4005

http://ijssurgery.com/content/11/1/5

This information is current as of April 26, 2023.

Email Alerts Receive free email-alerts when new articles cite this article. Sign up at: http://ijssurgery.com/alerts

The International Journal of Shing Surgerh 2397 Waterbury Circle, Suite 1,

Aurora, IL 60504, Phone: +1-630-375-1432

(C) 2017 ISASS. All Rights Reserved. 


\section{Surgical Revision after Sacroiliac Joint Fixation or Fusion}

Katie Spain, BS, Timothy Holt, MD

Montgomery Spine Center, Montgomery, AL

\section{Abstract}

\section{Background}

Minimally invasive sacroiliac joint (SIJ) fusion has been shown to be safe and effective for the treatment of SIJ dysfunction. Multiple devices are available to perform SIJ fixation or fusion. Surgical revision rates after these procedures have not been directly compared.

\section{Methods}

We retrospectively identified all patients in our practice who underwent SIJ fixation or fusion between 2003 and 2015. Using both chart review and focused contact with individual patients, we determined the likelihood of surgical revision. Revision rates were compared using Kaplan-Meier survival analysis.

\section{Results}

Thirty-eight patients underwent SIJ fixation with screws and 274 patients underwent SIJ fusion using triangular titanium implants. Four-year cumulative revision rates were $30.8 \%$ for fixation and $5.7 \%$ for fusion.

\section{Conclusions}

In our study, SIJ fixation with screws had a much higher revision rate compared to SIJ fusion with triangular titanium implants designed for bone adherence.

MINIMALLY INVASIVE SURGERY

KEYWORDS: SACROILIAC JOINT FUSION, SACROILIAC JOINT FIXATION, REVISION SURGERY, SURVIVAL ANALYSIS

VOLUME 11 ISSUE 1 DOI: 10.14444/4005

PAGES $24-30$

\section{Background}

The sacroiliac joint (SIJ) is increasingly recognized as a common cause of chronic low back pain. In patients presenting for evaluation of low back pain, the SIJ may play a role in $15-30 \%$ of cases. ${ }^{1-5}$ The SIJ is even more commonly suspected (up to $40 \%{ }^{6,7}$ ) as a source of low back pain in patients who have undergone prior lumbar fusion, possibly due to adjacent segment degeneration. Currently available treatment options for SIJ dysfunction include physical therapy, ${ }^{8}$ SIJ steroid injections, ${ }^{9,10} \mathrm{RF}$ ablation of the lateral branches of the sacral nerve roots, ${ }^{11,12}$ and open ${ }^{13}$ or minimally invasive ${ }^{14-18}$ SIJ surgery. Two recently published surgery vs. non-surgery randomized clinical trials of SIJ fusion using triangular titanium implants (TTI, iFuse Implant System, SI-BONE, Inc., San Jose, CA) showed that subjects undergoing SIJ fusion had large and statistically superior improvements in SIJ pain, pain-related disability and quality of life compared to those randomized to non-surgical care. $^{19,20}$
Several approaches and implants are available to perform minimally invasive SIJ fixation or fusion, including dorsal and lateral transfixing approaches. Moreover, strategies can include fixation only or fixation plus fusion. Fusion strategies include devices with coatings that have previously been shown to promote bone ongrowth ${ }^{21-23}$ or joint disruption with placement of graft materials.

Published literature on the dorsal approach is sparse $^{24-26}$ and some studies report very little improvement with this approach. ${ }^{24}$ In contrast, the published literature on lateral transfixing approaches is larger, with a small number of reports of hollow modular anchor screws $\mathrm{s}^{27-29}$ and a larger number of reports of TTI, including retrospective case series, ${ }^{15,16,30-34} \mathrm{a}$ combined multicenter analysis,${ }^{35}$ a prospective multicenter study ${ }^{36}$ and two prospective randomized trials. $^{19,20}$

The need to revise a surgically fused joint is a topic of interest to surgeons and their patients. As report- 
ed by the manufacturer, the revision rate after SIJ fusion using TTI is low (3.6\% at 4 years) ${ }^{37}$ and clinical trials have shown similar revision rates. TTI are specifically designed for SIJ fusion, with the triangular shape preventing rotational motion and the porous coating promoting biological fixation in bone. The extent to which this design improves over SIJ fixation with screws is not known. Herein we report a comparison of surgical revision rates between these two approaches.

\section{Methods}

Patients at a single spine surgeon practice who were at least 19 years old at the time of surgery and underwent SIJ fixation or fusion were identified through manual review and querying office billing databases. The fixation procedure was performed using cannulated $7.2 \mathrm{~mm}$ diameter stainless steel screws (Synthes, Figure 1. Postoperative AP pelvic x-ray showing typical results from SIJ fixation (left, A) and SIJ fusion (right, B). Figure 1a) as follows. With the patient in the prone position on a Jackson table, 2 or 3 guidewires (depending on patient body habitus) were inserted under fluoroscopic guidance across the SIJ. Following confirmation of pin placement, a $5.5 \mathrm{~mm}$ drill was used to drill across the joint and about 2.5 $\mathrm{mm}$ into the sacrum. Screws were placed and final imaging was done in the AP, outlet, and inlet views. Live fluoroscopy was also utilized in a 180-degree arc to ensure purchase across the joint. The entire procedure was performed through small $(2-5 \mathrm{~mm})$ punctures thru the skin in a percutaneous fashion. SIJ fusion with TTI (Figure 1. Postoperative AP pelvic $x-$ ray showing typical results from SIJ fixation (left, A) and SIJ fusion (right, B).Figure 1b) was performed as previously described. ${ }^{30}$ All procedures were performed under general anesthesia and using fluoroscopic guidance. Through chart review, demographic information and index surgery date were collected and recorded in a study database. Patients known to be dead were reviewed but did not otherwise participate in telephone calls (see below). Patients who underwent revision by the practice's surgeon (TH) were identified, and the circumstances of revision were noted through review of operative notes and clinic charts. Each patient's date of last clinic visit was identified.
Patients who had not been seen within 120 days of data collection were contacted by telephone. If contacted, verbal consent was obtained for further study participation. Each participating patient was reminded of his/her SIJ fixation or fusion by the study surgeon. Using lay language, the patient was asked whether the index side had undergone surgical revision by a physician other than the study author. If a revision took place unknown to the authors, an operative note was obtained (no such cases were observed). If the patient could not be contacted or refused to speak with study authors, this was noted in the study database. The study was approved by a regional institutional review board prior to initiation. The study was sponsored by SI-BONE, Inc. (which manufactures the TTI used for SIJ fusion in our cohort).

Baseline characteristics were compared across cohorts using t tests or Wilcoxon tests for continuous variables and chi-squared tests for nominal variables. The cumulative likelihood of SIJ revision surgery

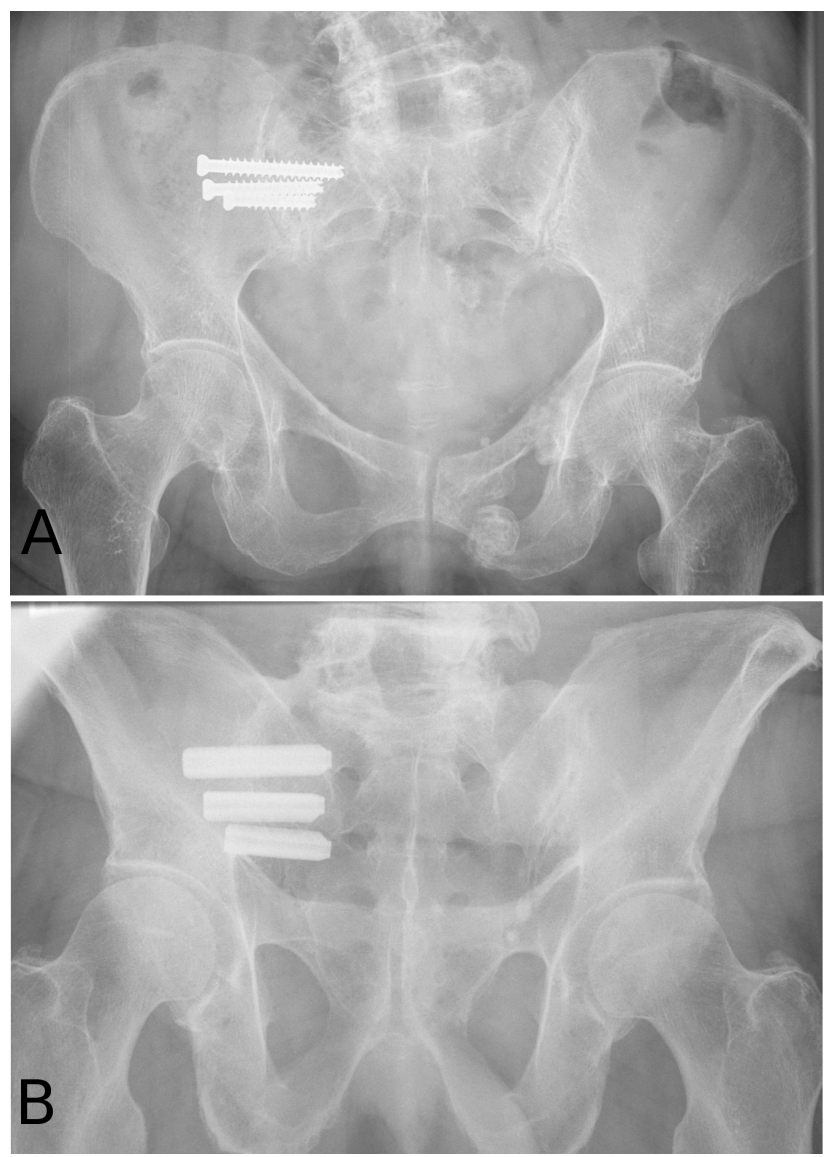

Fig. 1. Postoperative AP pelvic $x$-ray showing typical results from SIJ fixation (A) and SIJ fusion (B). 
was calculated using Kaplan-Meier analysis. ${ }^{38}$ Analysis was done at the "side" level (to account for a small proportion of patients who underwent bilateral SIJ fusion.) For patients who underwent revision, time was calculated as the number of days from surgery to first revision. For patients who did not undergo revision surgery, follow-up time was calculated as surgery date to either last clinic visit or the date of telephone contact. In a small number of patients, the chart could not be located or the index surgery date could not be identified; these patients were removed from the analysis. The log-rank statistic was calculated. Demographic factors possibly predicting the likelihood of surgical revision were explored using a similar approach. All statistical analysis was performed using $\mathrm{R}^{39}$

\section{Results}

According to available records, 274 patients underwent index SIJ fusion using triangular titanium implants (TTI) and 38 patients underwent SIJ fixation using screws. Records from 20 patients (11 TTI and 9 screw) could not be located (Figure 2). Demographic and clinical characteristics of included patients are shown in Table 1. Age was higher by about 8 years in the SIJ fusion group but gender and body mass index were similar. Patients undergoing SIJ fixation underwent surgery approximately 6 years before those undergoing SIJ fusion with TTI.

All patients whose charts were located and who were

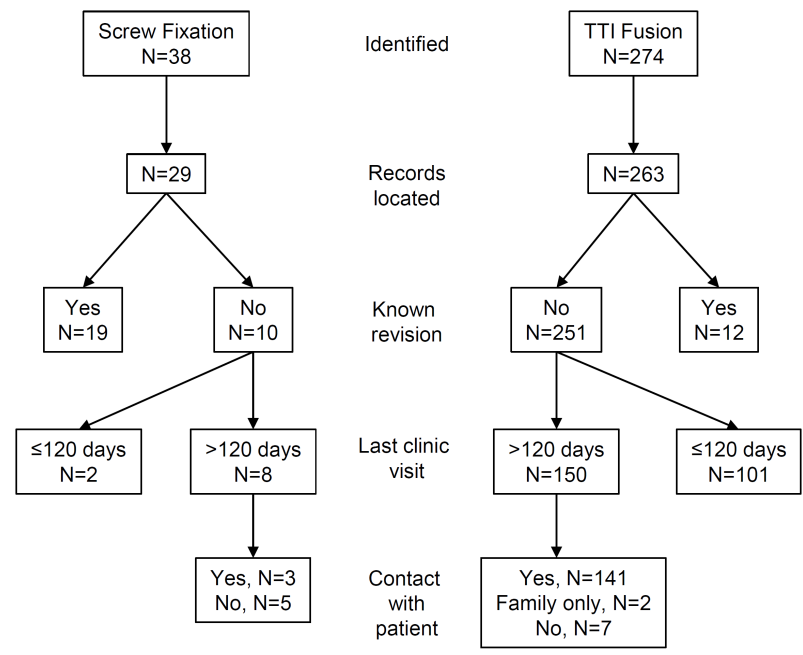

Fig. 2. Patient flow diagram. seen more than 120 days prior to study start were telephoned. Of the patients not known to have undergone revision who were last seen in clinic more than 120 days prior to study start, $91.1 \%$ were successfully contacted, $7.6 \%$ could not be contacted, and in $1.3 \%$ contact was established with a family member but not the patient himself/herself. No patient contacted by phone had undergone SIJ revision by another surgeon. Mean (median) follow-up time was 2.8 (3.2) years in the SIJ fusion group and 4.6 (4.9) years in the SIJ fixation group.

Based on review of clinic charts, a total of 31 patients underwent SIJ revision (19 in the fixation group and 12 in the SIJ fusion group). Revision was typically for pain recurrence, and some patients showed evidence of radiolucencies around implants (Figure 3). Using survival analysis techniques, the cumulative probability of revision was lower in the fusion group compared to the fixation group (Figure 4, $\mathrm{p}<.0001$ ); the 4 -year cumulative probability of revision in the fusion group was $5.7 \%$ in the fusion group and $30.8 \%$ in the fixation group. As of the longest follow-up time point, the cumulative probability of revision in the screw group was $79.8 \%$. Subgroup analysis showed no predictors of revision other than implant used.

\section{Discussion}

SIJ fusion is an increasingly accepted surgical treatment option for chronic SIJ dysfunction related to degeneration or disruption of the SIJ. Both SIJ fixation and SIJ fusion work by acutely stabilizing the

\begin{tabular}{|l|r|r|r|}
\hline Table 1. Demographic characteristics of patients undergoing SIJ fusion. \\
\hline Characteristic & $\begin{array}{r}\text { SIJ Fusion } \\
\text { (TTI*) } \\
(\mathbf{n = 2 6 3 )}\end{array}$ & $\begin{array}{r}\text { SIJ Fixation } \\
\text { (Screw) } \\
(\mathbf{n = 2 9 )}\end{array}$ & $\begin{array}{r}\text { P- } \\
\text { value }\end{array}$ \\
\hline Age, mean (range) & $54.3(24.0-85.0)$ & $46.6(27.0-61.0)$ & $<.0001$ \\
\hline BMI, mean (range) & $32.7(16.3-65.5)$ & $33.8(22.0-47.3)$ & 0.4703 \\
\hline N (\%) female & $63.1 \%(166)$ & $55.2 \%(16)$ & 0.5247 \\
\hline $\begin{array}{l}\text { Primary underlying cause, N } \\
\text { (\%) } \\
\text { Osteoarthritis }\end{array}$ & $260(98.9 \%)$ & $29(100.0 \%)$ & 1.0 \\
Trauma & $3(1.1 \%)$ & $0(0.0 \%)$ & \\
\hline $\begin{array}{l}\text { Year of surgery, median } \\
\text { (range) }\end{array}$ & $\begin{array}{r}2012 \\
(2011-2016)\end{array}$ & $(2004-2011)$ & $<.0001$ \\
\hline *TTI = triangular titanium implant & & & \\
\hline
\end{tabular}

Downloaded from http://ijssurgery.com/ by guest on April 26, 2023 
painful joint. SIJ fusion allows long-term immobility as a result of adherence of the bone to the lateral transfixing implant as well as bone growing in the SIJ itself. ${ }^{33}$

Surgical approaches and strategies (and associated devices) for the treatment of SIJ dysfunction vary. Several devices are available for a lateral transfixing approach, including screw-based devices and triangular titanium implants (TTI, iFuse Implant System). The literature for TTI includes 2 prospective randomized controlled trials, a large prospective study and several case series. TTI are designed both to resist rotational motion after insertion and to promote biological fixation in bone.

In our practice, we switched from screws to TTI in early 2012. We noticed that a much smaller proportion of patients returned to clinic with complaints of continued SIJ pain. Surgical revision was required in a large proportion of patients who underwent screwbased fixation. In contrast, the surgical revision rate

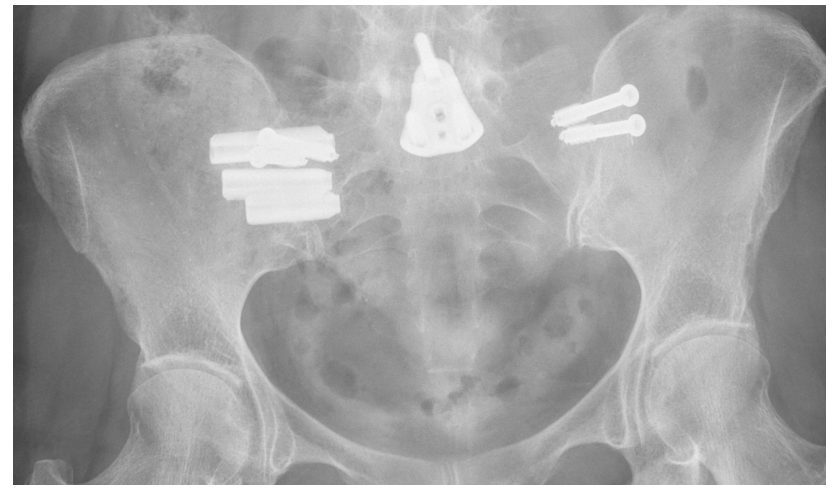

Fig. 3. Revision of right-sided screw fixation with TTI.

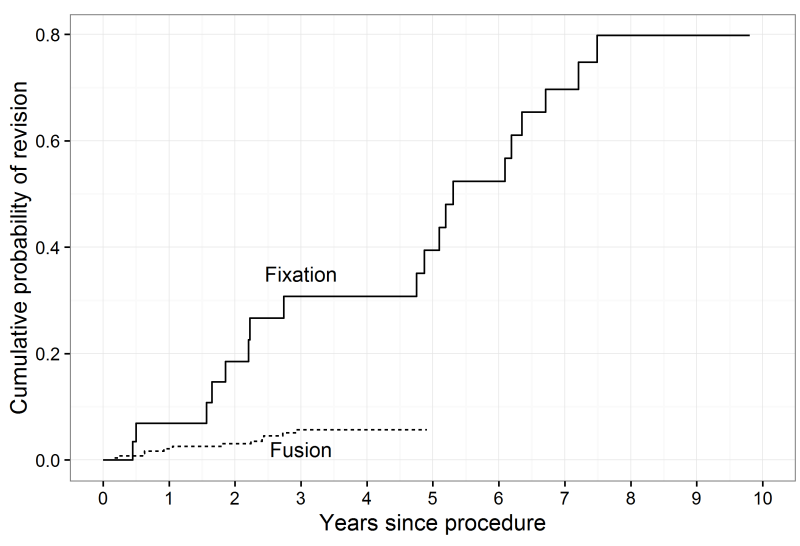

Fig. 4. Cumulative probability of revision surgery after either SIJ fusion surgery using TTI or SIJ fixation using screws. when using TTI was low, and similar to that reported in the literature. ${ }^{37}$

The failure mode in patients undergoing screw fixation was primarily loosening and recurrence of pain. The failure mode for patients undergoing TTI was traumatic fracture of the iliac wing secondary to a fall ( 1 case), malposition of the implant and loosening of the implant(s). It is our belief that standard surgical screws do not have a component that promotes biological fixation in bone, and screw loosening in other applications is common. Whether the modifications in screws incorporated into other FDA-cleared devices for SIJ fusion improve upon screw fixation is not known, and few published data are available to support improved effectiveness.

\section{Limitations}

Our study has several limitations. First, follow-up in the TTI group was shorter than in the SIJ fixation group, primarily because the TTI group was operated on more recently. Not all TTI patients have 4-year follow-up, so the 4-year revision rate is potentially subject to change. Second, we could not contact locate charts for some patients, potentially introducing a bias. Third, we could not contact a small number of patients. It is possible that patients who could not be contacted underwent revision surgery; however, no other surgeon local to our practice performs such procedures. Third, the time periods for the two groups differ, suggesting that temporal factors, such as surgeon learning curve, changes in OR policies, or postoperative care regimens, could play a role. However, the surgical technique used to perform the SIJ fixation and fusion procedures has not evolved in any important way. Differences are therefore mostly likely due to underlying device design. The number of patients in each group was markedly different, with a smaller number of cases undergoing SIJ fixation. The difference in number of cases is due to the availability of TTI devices that appeared to provide better pain relief, at least in the short-term. Observing better results, the desirability of performing the procedure increased, resulting in more treated patients. Finally, we did not assess pain relief or disability improvement, which have been addressed by other studies. 


\section{Conclusions}

Surgical revision after SIJ fixation using screws was required far more commonly compared to SIJ fusion using TTI. The device and surgical approach may make an important difference in the overall success of surgical treatments for SIJ dysfunction.

\section{References}

1. Bernard TN, Kirkaldy-Willis WH. Recognizing specific characteristics of nonspecific low back pain. Clin Orthop. 1987;(217):266-280.

2. Schwarzer AC, Aprill CN, Bogduk N. The sacroiliac joint in chronic low back pain. Spine. 1995;20(1):31-37.

3. Maigne JY, Aivaliklis A, Pfefer F. Results of sacroiliac joint double block and value of sacroiliac pain provocation tests in 54 patients with low back pain. Spine. 1996;21(16):1889-1892.

4. Irwin RW, Watson T, Minick RP, Ambrosius WT. Age, Body Mass Index, and Gender Differences in Sacroiliac Joint Pathology. Am J Phys Med Rehabil. 2007;86(1):37-44. doi:10.1097/

PHM.0b013e31802b8554.

5. Sembrano JN, Polly DW. How often is low back pain not coming from the back? Spine.

2009;34(1):E27-32. doi:10.1097/

BRS.0b013e31818b8882.

6. Liliang P-C, Lu K, Liang C-L, Tsai Y-D, Wang KW, Chen H-J. Sacroiliac joint pain after lumbar and lumbosacral fusion: findings using dual sacroiliac joint blocks. Pain Med Malden Mass.

2011;12(4):565-570. doi:10.1111/

j.1526-4637.2011.01087.x.

7. DePalma MJ, Ketchum JM, Saullo TR. Etiology of Chronic Low Back Pain in Patients Having Undergone Lumbar Fusion. Pain Med. 2011;12(5):732-739. doi:10.1111/j.1526-4637.2011.01098.x.

8. Jackson R, Porter K. The Pelvis and Sacroiliac Joint: Physical Therapy Patient Management Utilizing Current Evidence. In: Current Concepts of Orthopaedic Physical Therapy. 3rd ed. ; 2006.

9. Luukkainen R, Nissilä M, Asikainen E, et al. Periarticular corticosteroid treatment of the sacroiliac joint in patients with seronegative spondylarthropathy. Clin Exp Rheumatol. 1999;17(1):88-90.
10. Luukkainen RK, Wennerstrand PV, Kautiainen HH, Sanila MT, Asikainen EL. Efficacy of periarticular corticosteroid treatment of the sacroiliac joint in non-spondylarthropathic patients with chronic low back pain in the region of the sacroiliac joint. Clin Exp Rheumatol. 2002;20(1):52-54.

11. Cohen SP, Hurley RW, Buckenmaier CC, Kurihara C, Morlando B, Dragovich A. Randomized placebo-controlled study evaluating lateral branch radiofrequency denervation for sacroiliac joint pain. Anesthesiology. 2008;109(2):279-288. doi:10.1097/ ALN.0b013e31817f4c7c.

12. Patel N, Gross A, Brown L, Gekht G. A randomized, placebo-controlled study to assess the efficacy of lateral branch neurotomy for chronic sacroiliac joint pain. Pain Med Malden Mass.

2012;13(3):383-398. doi:10.1111/

j.1526-4637.2012.01328.x.

13. Buchowski JM, Kebaish KM, Sinkov V, Cohen DB, Sieber AN, Kostuik JP. Functional and radiographic outcome of sacroiliac arthrodesis for the disorders of the sacroiliac joint. Spine J Off J North Am Spine Soc. 2005;5(5):520-528; discussion 529. doi:10.1016/j.spinee.2005.02.022.

14. Sachs D, Capobianco R, Cher D, et al. One-year outcomes after minimally invasive sacroiliac joint fusion with a series of triangular implants: a multicenter, patient-level analysis. Med Devices Evid Res. 2014;7:299-304. doi:10.2147/MDER.S56491.

15. Cummings J Jr, Capobianco RA. Minimally invasive sacroiliac joint fusion: one-year outcomes in 18 patients. Ann Surg Innov Res. 2013;7(1):12. doi:10.1186/1750-1164-7-12.

16. Gaetani P, Miotti D, Risso A, et al. Percutaneous arthrodesis of sacro-iliac joint: a pilot study. $J$ Neurosurg Sci. 2013;57(4):297-301.

17. Vanaclocha V, Verdu-Lopez F, Sanchez-Pardo M, Gonzalbes-Esterelles L. Minimally Invasive Sacroiliac Joint Arthrodesis: Experience in a Prospective Series with 24 Patients. J Spine. 2014;3:5. doi: 10.4172/2165-7939.1000185.

18. Duhon BS, Cher DJ, Wine KD, Kovalsky D, Lockstadt $\mathrm{H}$. Triangular Titanium Implants for Minimally Invasive Sacroiliac Joint Fusion: A Prospective Study. Glob Spine J. in press.

19. Polly DW, Cher DJ, Wine KD, et al. Randomized Controlled Trial of Minimally Invasive Sacroili- 
ac Joint Fusion Using Triangular Titanium Implants Vs Nonsurgical Management for Sacroiliac Joint Dysfunction: 12-Month Outcomes. Neurosurgery. August 2015. doi:10.1227/ NEU.0000000000000988.

20. Sturesson B, Kools D, Pflugmacher R, Gasbarrini A, Prestamburgo D, Dengler J. Six-month outcomes from a randomized controlled trial of minimally invasive SI joint fusion with triangular titanium implants vs conservative management. Eur Spine $J$ Off Publ Eur Spine Soc Eur Spinal Deform Soc Eur Sect Cerv Spine Res Soc. May 2016. doi:10.1007/ s00586-016-4599-9.

21. Hallan G, Lie SA, Furnes O, Engesaeter LB, Vollset SE, Havelin LI. Medium- and long-term performance of 11,516 uncemented primary femoral stems from the Norwegian arthroplasty register. $J$ Bone Joint Surg Br. 2007;89(12):1574-1580. doi:10.1302/0301-620X.89B12.18969.

22. Engh CA, Culpepper WJ, Engh CA. Long-term results of use of the anatomic medullary locking prosthesis in total hip arthroplasty. J Bone Joint Surg Am. 1997;79(2):177-184.

23. Meding JB, Galley MR, Ritter MA. High survival of uncemented proximally porous-coated titanium alloy femoral stems in osteoporotic bone. Clin Orthop. 2010;468(2):441-447. doi:10.1007/ s11999-009-1035-z.

24. Endres S, Ludwig E. Outcome of distraction interference arthrodesis of the sacroiliac joint for sacroiliac arthritis. Indian J Orthop. 2013;47(5):437-442. doi:10.4103/0019-5413.118197. 25. Wise CL, Dall BE. Minimally invasive sacroiliac arthrodesis: outcomes of a new technique. J Spinal Disord Tech. 2008;21(8):579-584. doi:10.1097/ BSD.0b013e31815ecc4b.

26. Beck CE, Jacobson S, Thomasson E. A Retrospective Outcomes Study of 20 Sacroiliac Joint Fusion Patients. Cureus. 2015;7(4):e260. doi:10.7759/ cureus.260.

27. Khurana A, Guha AR, Mohanty K, Ahuja S. Percutaneous fusion of the sacroiliac joint with hollow modular anchorage screws: clinical and radiological outcome. J Bone Joint Surg Br.

2009;91(5):627-631. doi:10.1302/

0301-620X.91B5.21519.

28. Mason LW, Chopra I, Mohanty K. The percuta- neous stabilisation of the sacroiliac joint with hollow modular anchorage screws: a prospective outcome study. Eur Spine J. 2013;22(10):2325-2331. doi:10.1007/s00586-013-2825-2.

29. Al-Khayer A, Hegarty J, Hahn D, Grevitt MP. Percutaneous sacroiliac joint arthrodesis: a novel technique. J Spinal Disord Tech. 2008;21(5):359-363. doi:10.1097/BSD.0b013e318145ab96.

30. Rudolf L. Sacroiliac Joint Arthrodesis-MIS Technique with Titanium Implants: Report of the First 50 Patients and Outcomes. Open Orthop J. 2012;6:495-502. doi:10.2174/1874325001206010495. 31. Sachs D, Capobianco R. Minimally invasive sacroiliac joint fusion: one-year outcomes in $40 \mathrm{pa}-$ tients. Adv Orthop. 2013;2013:536128. doi:10.1155/ 2013/536128.

32. Schroeder JE, Cunningham ME, Ross T, Boachie-Adjei O. Early Results of Sacro-Iliac Joint Fixation Following Long Fusion to the Sacrum in Adult Spine Deformity. Hosp Spec Surg J. 2013;10(1):30-35. doi:10.1007/s11420-013-9374-4. 33. Rudolf L, Capobianco R. Five-Year Clinical and Radiographic Outcomes After Minimally Invasive Sacroiliac Joint Fusion Using Triangular Implants.

Open Orthop J. 2014;8:375-383. doi:10.2174/ 1874325001408010375 .

34. Vanaclocha VV, Verdú-López F, Sánchez-Pardo, M, et al. Minimally Invasive Sacroiliac Joint Arthrodesis: Experience in a Prospective Series with 24 Patients. J Spine. 2014;3(5). doi:10.4172/ 2165-7939.1000185.

35. Graham Smith A, Capobianco R, Cher D, et al. Open versus minimally invasive sacroiliac joint fusion: a multi-center comparison of perioperative measures and clinical outcomes. Ann Surg Innov Res. 2013;7(1):14. doi:10.1186/1750-1164-7-14.

36. Duhon B, Bitan F, Lockstadt H, Kovalsky D, Cher D, Hillen T. Triangular Titanium Implants for Minimally Invasive Sacroiliac Joint Fusion: 2-Year Follow-Up from a Prospective Multicenter Trial. Int J Spine Surg. 2016;10:Article 13. doi:10.14444/3013. 37. Cher DJ, Reckling WC, Capobianco RA. Implant Survivorship Analysis after Minimally Invasive Sacroiliac Joint Fusion using the iFuse Implant System. Med Devices Auckl NZ. doi:10.2147/ mder.s94885.

38. Kaplan EL, Meier P. Nonparametric Estimation 
from Incomplete Observations. J Am Stat Assoc. 1958;53(282):457-481. doi:10.2307/2281868.

39. R Core Team (2013). R: A Language and Environment for Statistical Computing. Vienna, Austria http://www.R-project.org/.

40. Sachs D, Kovalsky D, Redmond A, et al. Durable intermediate- to long-term outcomes after minimally invasive transiliac sacroiliac joint fusion using triangular titanium implants. Med Devices (Auckl).. 2016;9:213-22. doi:10.2147.mder.s109276.

Disclosures \& COI

The study described herein was sponsored by SIBONE. SI-BONE staff helped with statistical analy- sis. Dr. Tim Holt is a consultant to SI-BONE. Ms. Katie Spain has no financial conflict.

\section{Corresponding author}

Katie Spain, Montgomery Spine Center, 257 Winton M Blount Loop, Montgomery, AL 36117. kspain32@gmail.com.

Published 19 January 2017.

This manuscript is generously published free of charge by ISASS, the International Society for the Advancement of Spine Surgery. Copyright $\odot 2017$ ISASS. To see more or order reprints or permissions, see http://ijssurgery.com. 